rev.relac.int.estrateg.segur.13(2):153-185,2018

\title{
La importancia de Corea del Norte para China*
}

\author{
Camilo Patiño García**
}

\section{Resumen}

El presente trabajo examina la relación de reciprocidad entre la República Popular de China (China) y la República Popular Democrática de Corea (Corea del Norte), en cuanto a la alianza y dependencia. A partir de una posición neorrealista en Relaciones Internacionales se puede afirmar que mientras Corea del Norte depende de China para su estabilidad interna y seguridad externa, China mantiene esta alianza como elemento prioritario de seguridad geopolítica y estabilidad regional para su desarrollo económico. En el artículo se plantea una visión histórica de la relación para mostrar el factor de conveniencia en sus constantes distanciamientos y acercamientos; se analizan los componentes militares y económicos como elementos de poder, al igual que el institucionalismo internacio-

* Este artículo forma parte del proyecto de investigación sobre Economía Política en Asia Pacífico, del Departamento de Artes, Educación y Humanidades del Centro Universitario de la Costa de la Universidad de Guadalajara, Jalisco, México.

** Magíster en Ciencias Sociales con especialidad en Estudios Internacionales en Asia Pacífico. Profesor titular de la Universidad de Guadalajara, Jalisco, México. Miembro de la Asociación Mexicana de Estudios Internacionales. Correo electrónico: camilo.garcia@cuc. udg.mx. 
nal como marco de explicación de la política de China hacia Corea del Norte. La evidencia señala que las acciones de China para apoyar a Corea del Norte, sobre todo en el ámbito económico y político, no están sujetas al alejamiento norcoreano de las normas y estándares del sistema internacional, sino a la estructuración de una península coreana estable, con un aliado que le permite un equilibrio de poder geopolítico no supeditado a otros Estados.

Palabras clave: conflicto internacional; negociación; relaciones internacionales; sanción; seguridad nacional.

\title{
The Importance of North Korea to China
}

\begin{abstract}
This paper examines the reciprocal relationship between the People's Republic of China (China) and the Democratic People's Republic of Korea (North Korea) in terms of alliance and dependence. From a neorealist position in international relations, it may be affirmed that, although North Korea depends on China for its internal stability and external security, China maintains this alliance as a priority element of geopolitical security and regional stability for its economic development. It also presents a historical view of the relationship to evince the convenience factor in their constant distancing and approach, analyzes the military and economic components as power elements and international institutionalism as an explanation for China's policy toward North Korea. Evidence indicates that China's actions in support of North Korea, especially economically and politically, are not subject to the North Korean deviation from the rules and standards of the international system, but to the structuring of a stable Korean peninsula with an ally that enables geopolitical power balance not subordinated to other states.
\end{abstract}

Keywords: international conflict; international relations; national security; negotiation; penalty.

\section{A importância da Coreia do Norte para a China}

\section{Resumo}

Este trabalho examina a relação de reciprocidade entre a República Popular da China (China) e a República Popular Democrática da Coreia (Coreia do Norte), em quanto à aliança e à dependência. A partir de uma posição neorrealista 
em Relações Internacionais é possível afirmar que enquanto a Coreia do Norte depende da China para sua estabilidade interna e segurança externa, a China mantém esta aliança como elemento prioritário de segurança geopolítica e estabilidade regional para o seu desenvolvimento econômico. No artigo propõe-se uma visão histórica da relação para mostrar o fator de conveniência em suas constantes distanciamentos e aproximações; analisam-se os componentes militares e econômicos como elementos de poder, assim como o institucionalismo internacional como marco de explicação da política da China com relação à Coreia do Norte. A evidência sinala que as ações da China para apoiar a Coreia do Norte, sobre tudo no âmbito econômico e político, não estão sujeitas ao afastamento da Coreia do Norte das normas e padrões do sistema internacional, mas sim à estruturação de uma península coreana estável, com um aliado que the permite um, equilíbrio de poder geopolítico não supeditado a outros Estados.

Palavras-chave: conflito internacional; negociação; relações internacionais; sanção; segurança nacional.

\section{Introducción}

La constante amenaza a la estabilidad regional del noreste asiático por parte de Corea del Norte con sus programas de armas y con sus agresiones a Japón, a la República de Corea (Corea del Sur) y a Estados Unidos (EE. UU.), se remonta al fin de la Guerra Fría y afecta el equilibrio de poder regional. A pesar de lo anterior, los Estados amenazados —en especial Japón y Corea del Sur - no han podido resolver esta problemática, que implica un riesgo a su existencia: una Corea del Norte que se ve hostigada puede utilizar su armamento nuclear como forma de defensa e incluso como una herramienta ofensiva. En este contexto, China es un actor primario, pues lo que ocurre en la península de Corea afecta sus intereses de seguridad y desarrollo económico. Ante esta situación, China juega un doble papel político: primero como un Estado que puede ayudar a solucionar la problemática, pero también como el único país que resguarda al régimen norcoreano. 
La relación entre China y Corea del Norte está ligada entrañablemente a su proximidad geográfica e historia compartida ${ }^{1}$, pero también por más de medio siglo, desde el fin de la Segunda Guerra Mundial, a su afinidad política, cooperación y alianza geoestratégica. Bajo el discurso de una bandera común de ideología socialista se había amparado una asociación que creaba un balance de poder geopolítico, no solo en la península de Corea sino en todo el noreste asiático, una asociación que continúa aun cuando dicho discurso ya se agotó. Sin embargo, podemos apreciar la relación entre estos Estados a partir de los acercamientos y alejamientos que corresponden a los emplazamientos del Sistema Internacional, una relación en la que, en todo caso, China se ha mantenido siempre como una constante, como un factor de supervivencia para Corea del Norte.

Se utilizará un acercamiento realista para explicar esta situación a través del análisis de factores de poder. En la primera parte de este trabajo se estudiarán dos etapas históricas. Primero, aquella que abarca de 1950 a 1961, en la que se desarrolla la Guerra de Corea, que marcó la alianza entre ambos Estados e introdujo a la región en la Guerra Fría; se trata de un mo- mento en el que la entonces Unión de Repúblicas Socialistas Soviéticas (URSS) y China apoyaron a Corea del Norte. La segunda etapa es el periodo de 1961 a 1993, en el que se evidencia una fuerte influencia soviética sobre Corea del Norte hasta la caída del bloque soviético, momento crucial en la reconstrucción de China, que se recupera de la Revolución Cultural (1966) e inicia un proceso de apertura política y económica, razón por la que se acerca a Corea del Sur y a Estados Unidos. En esta etapa se da un cambio regional e internacional para Corea del Norte; se desarticula su antiguo balance de poder con China y la URSS, obligándolo a buscar otras estrategias de sobrevivencia como fue su acercamiento hacia EE. UU.

La segunda parte del documento se centrará en las relaciones comprendidas en el periodo de 1993 a 2017, época en la que Corea del Norte propugna una creciente militarización, aunque en un contexto regional con mayor integración y con la presencia de China, como potencia no solo nuclear sino económica y política. Se examinará primero el interés de China por conservar una península coreana estable y sin influencias de otros Estados, y se mostrará cómo, en el aspecto político y económico, China ha utiliza-

1 La relación social y cultural entre la península de Corea y China tiene antecedentes en épocas antiguas: de acuerdo con Mark Cartwright (2016) y Michael J. Seth (2010) podemos rastrear esta historia desde la Edad de Bronce. Además, la influencia que ejerció China como foco de civilización se plasma en el arte, y en la forma de gobierno y organización de la península de Corea. Parte de Corea fue ocupada por China bajo el mandato de la dinastía Qing, hasta antes de la invasión japonesa en el periodo de 1985-1910. La fundación de la República Popular Democrática de Corea (RPDC) se establece en 1948, tras la Segunda Guerra Mundial, cuando la península se dividió en dos Estados, Corea del Norte y Corea del Sur. 
do su poder e influencia para mantener al régimen norcoreano. Se expone que, a pesar de los cambios de las estructuras regionales, Corea del Norte continúa siendo un Estado cerrado con un enfrentamiento político y militar principalmente con Corea del Sur y Japón, y que representa una amenaza de estabilidad. Pese a esto, para China es de mayor importancia estratégica que Corea del Norte sobreviva a que sea intervenido por otros Estados, y le da más prioridad a sus intereses que a una posible reunificación de toda la península con una diligencia externa.

El trabajo se concentra en el análisis microinternacional, pues comprende las relaciones entre Estados a nivel regional; se emplea un método descriptivo con relaciones de causalidad directa. En la primera parte del documento, se maneja un análisis histórico a largo plazo, y se observan los cambios de carácter sistémico, tanto a nivel regional como particular de cada Estado, cambios que provocan una variación de factores endógenos y de estructuras, pero que, por otra parte, mantienen una constante en las relaciones de causalidad de China como aliado de Corea del Norte. En la segunda parte, se utilizan variables operativas de los factores económicos, políticos y militares, y se considera su evolución para extrapolar su incidencia en el actuar de China.

\section{Desde el neorrealismo}

Para China, su conversión en una potencia implica la protección de la península de Corea, así como de la región del noreste asiático; la idea es mantener el territorio libre de conflictos armados o de intervenciones que lleven a un balance de poder no favorable. Acorde con las proposiciones neorrealistas, las acciones de los Estados como principales actores en el sistema internacional anárquico son racionales y obedecen a la búsqueda de poder, seguridad y supervivencia, motivaciones centrales para poder entender el fenómeno, ya que desencadenan una conducta común (Waltz, 1988). En este sentido, las acciones responden a las intenciones y a la preocupación creada por el mismo sistema anárquico, que no significa caótico, sino que se refiere, en este caso, al sistema que no cuenta con una gobernanza, por lo que cada Estado es soberano y busca el poder que garantice su supervivencia ante un entorno peligroso e incierto.

Ahora bien, el poder tiene distintas formas: hay poder económico, militar, político, diplomático, etc.; para los neorrealistas, todo Estado posee el llamado "poder militar", con el cual se puede agredir e incluso destruir a otro Estado (Mearsheimer, 1994-1995). Una característica esencial heredada del realismo es la idea de que ningún Estado puede asegurar totalmente cuáles son las intenciones de otro Estado, dado que estos compiten por los mismos fines. Por ende, cada uno de los Estados debe tener el suficiente poder para defenderse y sobrevivir; estos, por lo tanto, se encuentran buscando de forma permanente su seguridad. 
Así, también es permanente la competencia por la supervivencia. Esto se evidencia en la situación de China, cuyo estatus dentro del sistema internacional se ve amenazado constantemente por las posibles intervenciones de otros Estados que afecten su integridad territorial, amenacen el sistema regional y, por ende, sus intereses como Estado. De tal forma, su supervivencia se sostiene en el fortalecimiento de su seguridad, y Corea del Norte, así como toda la península de Corea, representa precisamente una zona de seguridad, que históricamente ha estado en forcejeo con otros Estados (EE. UU. y Rusia).

John J. Mearsheimer (1994-1995) establece que cada Estado, con el fin de asegurar su supervivencia, busca ser el que ejerce más poder (hegemonía), y evita a su vez que algún otro tenga esa posición de dominio; se trata de un comportamiento constante de ofensiva-defensiva. En este mismo sentido, John H. Herz (1950) considera que los Estados pueden encontrarse en un dilema de seguridad cuando, para defenderse de otro que pueda amenazarlos, adquieren más poder con el fin de escapar de esta situación de vulnerabilidad, puesto que esa misma reacción la tendrán otros Estados, que también iniciarán la búsqueda de mayor poder con el mismo propósito. Se crea así un círculo de competencia por el poder como garantía de la seguridad. Aunque Waltz (1988) no rechaza que la hegemonía sea una aspiración de los Estados, sí delibera sobre su racionalidad, ya que el Estado hegemó- nico enfrenta mayores riesgos en su supervivencia, pues despierta nuevos conflictos con otros Estados que se sentirían amenazados por su poder. Es necesario tener en cuenta, por lo tanto, una característica esencial: la existencia de una distribución de capacidades (balance de poder), que influye y condiciona las políticas de los Estados en su actuar, y ello determina (limita o modifica) su relación con los otros actores; es decir, un equilibrio que proporciona cierta estabilidad, ya que algunos Estados cuentan con capacidades similares, lo cual confina las acciones de amenaza a su existencia, sobre todo entre los que concentran mayor poder.

Las relaciones entre los Estados están estratificadas en el sistema. Sin embargo, dicha estructura no es fija, debido a que los Estados buscan constantemente modificar su posición dentro de este sistema, y los cambios o transformaciones que se producen llevan a un movimiento de la distribución de las capacidades y del poder entre aquellos. Tal repartición de poder de los Estados determina parámetros en las relaciones, y son los de mayor poder los que definen las estructuras. Entonces, al tomar parte de las actividades en el sistema, el Estado que busca la supervivencia actúa bajo su propio consentimiento para lograr sus intereses o bajo la coerción forzada.

En este sentido, la búsqueda de poder y seguridad que ha mostrado China en las últimas décadas no se define solo por su influencia en temas económi- 
cos, sino también en los políticos y militares, en los que se evidencia su intención de contener un equilibrio de poder en la región que imposibilite a otros Estados para intervenir. Lo anterior también explica el comportamiento de Corea del Norte, que procura su supervivencia a través de alianzas y de crecimiento militar, sin optar por la posibilidad de una integración a los distintos regímenes internacionales, lo cual propicia un dilema de seguridad.

Un tema en el que se debe profundizar, para entender el comportamiento de los Estados en su constante interacción, es la colaboración en el sistema anárquico. Si bien los Estados no pueden confiar con total certeza en otros, eso no significa que no puedan colaborar en determinadas circunstancias. Al respecto, la búsqueda de supervivencia de un Estado puede apoyarse en los mismos objetivos de otro. Tal es la motivación para formar una alianza. De acuerdo con Mearsheimer (19941995), las alianzas son temporales y solo buscan satisfacer los intereses individuales. Así, distintas formas de colaboración, como acuerdos, tratados, instituciones, entre otras, son un reflejo de distribución de poder momentánea y son motivadas por los cálculos de ganancias de los Estados. En este sentido, China estableció una política de pacificación y de integración en procesos económicos con los Estados de la región, pero también creó instituciones en prácticamente todos los ámbitos, incluyendo alianzas estratégicas de seguridad, que han hecho aportes para mantener una estabilidad por medio de elementos de interdependencia e intereses comunes. Como señala el neorrealismo, las grandes potencias siguen el patrón de establecer las estructuras y son quienes constituyen la mayor parte de las Instituciones que agrupan a todo el sistema, como medios de poder y equilibrio. Por ende, no son estos acuerdos de colaboración los que determinan el comportamiento de los Estados, sino los Estados quienes deciden seguir las normas con base a su propio interés.

Con este marco explicativo se expone cómo las acciones de militarización y confrontación de Corea del Norte, que amenazan la estabilidad regional necesaria para que China continúe su desarrollo económico, no son un motivo para que ambos países se alejen y, por lo tanto, se vea afectada su relación de apoyo. El interés de China no se centra, entonces, en desarticular bajo amenazas al régimen norcoreano. Por el contrario, China ha establecido una postura de equilibrio de poder a nivel regional e internacional, que limita las acciones unilaterales de otros Estados en contra de Corea del Norte. Con lo cual, siguiendo la teoría neorrealista, se deduce que Corea del Norte representa un pilar de intereses geopolíticos y de seguridad para China.

Por último, aunque se aleja de la proposición neorrealista, es propicio establecer el objetivo de la seguridad para los Estados. Siguiendo a Barry Buzan (1998) desde su concepción más neorrealista, la seguridad que persiguen los Estados está compuesta de muchos 
elementos, pues implica pensar en aspectos políticos, militares, económicos, medioambientales y sociales, ya que el poder tiene distintas variables. La introducción de temas a la agenda de seguridad de un Estado debe establecer la relación entre un sector y su objetivo: la securitization (securitize), es decir, la agenda económica y política de China como factor clave de su actual política exterior. El desarrollo económico de China se vería amenazado por la inestabilidad del régimen de Corea del Norte o por una intervención norteamericana. De la misma forma, la política China de desarrollo pacífico en la región se ve amenazada por el apoyo que brinda o por su no intervención ante las acciones de Corea del Norte.

\section{La construcción histórica de las relaciones entre Corea del Norte y China}

Desde el inicio de la relación entre China y Corea del Norte se puede trazar un panorama de identidad compartida, que sirve como eje de intereses geopolíticos. Cuando termina la Segunda Guerra Mundial, los Estados que habían logrado imponerse como potencias, EE. UU. y la URSS, establecieron una ocupación militar en la península de Corea; fue el resultado de la liberación del territorio ante las fuerzas japonesas. Sin embargo, dicha ocupación también mostró el interés de ambas potencias por la región de Asia. Motivo por el cual se hizo un acuerdo de repartición territorial a partir del paralelo 38: la parte Norte de la península fue controlada por la URSS y la parte Sur por los EE. UU. Lo anterior propició la oportunidad para que estos Estados buscaran controlar permanentemente la península, instaurando su sistema ideológico y de administración. Para ello, conformaron dos grupos internos en Corea que buscaban establecer el nuevo gobierno en toda la península, bajo distintos sistemas.

Esto provocó la confrontación y la división de la península, como lo afirma el entonces Grupo de Inteligencia Central de Estados Unidos, en el Resumen Ejecutivo del comunicado del 3 de enero de 1947 sobre la situación de Corea. El conflicto se mantuvo y se reafirmó por las administraciones militares de EE. UU. y de la URSS, y se convirtió en el origen de un problema de identidad, de lucha independentista y de reunificación. Esto es lo que dice el documento mencionado:

Unidad e independencia son la aspiración dominante de la gente de Corea, mientras la división y ocupación conjunta por parte de Estados Unidos y la URSS son los factores gobernantes en la vida política y económica de la península. La promesa de independencia hecha en el Cairo, y confirmada en Yalta, no se ha cumplido. La división de Corea en el paralelo 38 se ha vuelto una barrera casi impenetrable entre las zonas estadounidenses $y$ 
soviéticas. $^{2}$ (Central Intelligence Group, 1947, p. 1)

Según el mismo resumen:

La política soviética en Corea está enfocada hacia el establecimiento de un Estado amigable que nunca servirá como base de ataque contra la URSS... La URSS intenta hacer a Corea del Norte autosuficiente mediante la subordinación política. Los soviéticos han dado a su zona un aspecto de autonomía al encomendar la administración a los COmités del pueblo, dominados por los comunistas coreanos. ${ }^{3}$ (Central Intelligence Group, 1947, p. 1)

Así, la Guerra de Corea (1950-1953) inició con la disputa entre los grupos formados en el Norte y en el Sur. Fue el intento norcoreano por recuperar el resto de la península lo que sirvió como justificación para el ingreso de tropas norteamericanas y surcoreanas al norte del paralelo 38. Esto propició la decisión de China, en 1950, de participar en el conflicto, con la ayuda económica y militar a los norcoreanos. En 1953, con la firma del Armisticio de Panmunjom, se puso un alto al conflicto y se determinó el trazado de las fronteras entre Corea del Norte y Corea del Sur; dicho armisticio fue firmado por Estados Unidos, China, Corea del Norte y el comando de la Organización de Naciones Unidas (ONU), es decir, por los principales actores involucrados.

Hoy en día aún se conservan y promocionan rastros de estos hechos: un ejemplo de ello es lo que ocurre en la ciudad de Dandong (China), donde se estableció, en 1993, un museo que conmemora la Guerra para ayudar a Corea del Norte y la resistencia a la agresión de Estados Unidos. Esta ciudad es emblemática, además, por limitar con la frontera de Corea del Norte; fue un punto de conflicto en la Guerra, y cuenta con el puente de la amistad, por el cual se moviliza el comercio entre ambos Estados (Song, 2012). Esto estimula la identidad de la heroica participación de China para ayudar a Corea del Norte.

En 1960, la URSS y China enfrentaron diferencias que desencadenaron el distanciamiento del gobierno dirigido por Mao del modelo soviético. Esto llevó a una pugna dentro de los países comunistas y la ruptura implicó para China una relación de dos vertientes

2 La traducción es del autor. El texto original en inglés dice: "Unity and independence are the dominant aspirations of the Korean people, while partition and joint occupation by US and USSR are the governing factors in the political and economic life of the peninsula. The promises of independence made at Cairo, and confirmed at Yalta, have not been fulfilled. The division of Korea at the 38th parallel has become an almost impenetrable barrier between the US and Soviet Zones".

3 La traducción es del autor. El texto original en inglés dice: "Soviet policy in Korea is directed toward the establishment of friendly state which will never serve as a base of attack upon the USSR... The USSR has attempted to make North Korea economically self-sufficient though politically subordinate. Soviets have given their zone a semblance of autonomy by entrusting the administration to a hierarchy of 'people's committees' dominated by the Korean Communists". 
con Corea del Norte: por un lado, el gobierno norcoreano lanzó serias críticas a la posición adoptada por China y se acercó como aliado a la URSS; por el otro, el conflicto de la Guerra Fría y la crucial importancia de la posición de la península de Corea obligaron a China a no permitir una ruptura en su esfera de influencia y, por ende, a no iniciar un conflicto con Corea del Norte. Por lo anterior, China mantuvo su apoyo a Corea del Norte, y en 1961 este se oficializó, a nivel de Estados, con la firma del Tratado de Amistad, Cooperación y Asistencia Mutua, que ofrecía una herramienta de alianza y seguridad en la estructura de balance de poder en la región, ante el esquema de confrontación en la Guerra Fría ${ }^{4}$.

De este modo, a nivel de política exterior regional, las relaciones entre estos Estados se enfrentaron a un "acomodo de seguridad", pero a nivel bilateral estaban marcados por trances de conflicto y acercamiento: esto se evidencia, por ejemplo, en la coexistencia de las disputas en sus fronteras por la región de Paektu, entre 1968 y 1969 —un asunto territorial que sigue sin resolverse- con los acercamientos revelados en las visitas de alto nivel para mantener sus relaciones. Para Quansheng Zhao (1996), China estructuró una política integradora, desde el nivel macro hasta el micro, que implicaba alinear su estabilidad interna con un proceso de seguridad externa; se trata del costo que implicaba la pérdida de una relación geoestratégica. Aunque para otros autores, como José Luis León (2005), existieron otros componentes: el pacto de camaradería entre Kim Il-sung y Mao se interpretó como un factor determinante para el mantenimiento de las relaciones de ambos Estados.

Durante los años setenta, China estableció una política de apertura de relaciones, suscitada principalmente por dos factores: estabilidad y desarrollo. A nivel regional, se veía amenazada ante la presencia de las dos potencias en disputa: Estados Unidos, un actor hostil que representaba una amenaza directa a su soberanía por el apoyo a Taiwán y, por otra parte, la Unión Soviética, que se consideraba un peligro por las diferencias ideológicas y su búsqueda de expansionismo. Ante esta coyuntura y sus planes internos de desarrollo, China modificó, en 1971, sus relaciones formales a nivel de sistema; se acercó a negociar con EE. UU., y reactivó su diplomacia como miembro de la ONU.

En 1972, se suscitó lo que podemos considerar un pronunciamiento oficial de diplomacia de cooperación sino-estadounidense, gracias a la visita del presidente Nixon a Pekín ${ }^{5}$. El pronunciamiento del Comunicado de

4 La Guerra Fría conformó un enfrentamiento del bloque a nivel regional con Japón y Corea del Sur en alianza con EE. UU., por un lado, y, por otro, la URSS, Corea del Norte, China, y los países socialistas del sureste asiático como Vietnam.

5 En 1972, el presidente de EE. UU., Richard Nixon, y el secretario de Estado, Henry Kissinger, realizaron visitas a China como parte de un acercamiento bilateral. 
Shanghái poseía matices claros que sugerían el interés de China en encontrar un equilibrio regional que le brindara elementos de contención ante la URSS. En dicha declaración, se estipula que China "nunca sería una súper potencia y se oponía a la hegemonía y poder político de cualquier tipo", mientras que los Estados Unidos declaraban respaldar el "derecho de las personas del Sur de Asia de construir su propio futuro en paz, libre de amenazas militares y sin que la región se volviera objeto de rivalidad de los grandes poderes" 6 (Shanghai Communiqué, 1972). En 1979, las relaciones entre ambos Estados se oficializaron.

Igualmente, es necesario notar que estos acercamientos tuvieron lugar en un periodo de transición interna en China, marcado por el cambio de poder, en 1978, en el Partido Comunista Chino (PCCh) y la entrada de Deng Xiaoping como principal líder. Así, China inició los procesos de reforma económica con un pronunciado activismo de política exterior, que consistía en el aseguramiento de su desarrollo con base a la apertura de relaciones económicas y políticas. Estas reformas requerían de cooperación en la región y a nivel internacional, con el fin de asegurar la estabilidad necesaria para su desarrollo. China realizó su acercamiento con los demás Estados de la región en su política de economía de mercado dirigida, dejando de lado los discursos ideológicos.
En 1987, con la apertura comercial de China y los cambios en el sistema regional, cuando la mayoría de los Estados sostenían una política económica comercial como factor de desarrollo, se incrementó el comercio regional, así como la necesidad de diálogo e integración mediante la creación de acuerdos y otras formas de institucionalización para dicho fin. Una consecuencia de ello fue la conformación, en 1989, del Foro de Cooperación Económica de Asia Pacífico (conocido COMO APEC, su sigla en inglés). En este contexto, China inició y/o acrecentó nexos económicos y políticos con todos los Estados de la región Asia Pacífico. Con relación a esto, fue relevante, para su vínculo con Corea del Norte, el restablecimiento oficial de las relaciones con la República de Corea (Corea del Sur), lo que en 1992 significó un mutuo reconocimiento diplomáti$\mathrm{co}, y$, por otra parte, la reconfiguración de las relaciones con Japón, que de acuerdo con su Ministro de Relaciones Exteriores fue fundamental, en cuanto pivote de la estabilidad y prosperidad regional (Ryutaro, 1997).

Pero también las relaciones con Corea del Norte habían sufrido cambios estructurales, dado el pivote de poder regional con la URSS. Hasta antes del fin de la Guerra Fría, Corea del Norte consolidó sus relaciones con China y la URSS. De tal forma, inició su reconstrucción e industrialización, gracias al apoyo económico y tecnológico que

6 Las traducciones son del autor del artículo. 
recibía, al mismo tiempo que intensificaba el manejo de una política de prevención que buscaba que estos Estados no crearan relaciones diplomáticas con Corea del Sur.

Sin embargo, durante los años ochenta, a la par que China inició su proceso de apertura, Corea del Sur también buscó la expansión de componentes de seguridad, mediante el aumento de relaciones diplomáticas y comerciales a nivel global: introdujo lo que se conoce Nordpolitik, que estructuraba la implementación de relaciones diplomáticas con los Estados del bloque socialista regional, sobre todo con China y la URSS, con quien empató la política Glásnost de Gorbachov, e incluso inició contacto y diálogo con Corea del Norte. La política implementada por el entonces líder surcoreano, Roh Tae-woo, tuvo sus primeros logros en 1988, en el marco de las olimpiadas de Seúl, con la creación de canales diplomáticos (Sanford, 1993). Para Corea del Norte, lo anterior representó un desafío a la seguridad, puesto que sus dos principales aliados compartían acercamientos con Corea del Sur. La respuesta de Corea del Norte hacia Corea del Sur fue el atentado en 1987 al vuelo 858 de Korean Air, que dejó 115 muertos, un acto declarado como terrorista.

En 1990, la desintegración de la URSS significó una disminución sustancial de ayuda económica para Corea del Norte; esto coincidió con una serie de desastres naturales, que provocaron que la industria agroalimentaria norcoreana se encontrara en problemas, crisis que se conoce como la Marcha de Hambruna (Arduous March). Lo anterior propició que Corea del Norte tuviera la necesidad de buscar su seguridad en un nuevo equilibrio de poder, por lo que inició relaciones de acercamiento con distintos Estados, sin importar su posición ideológica, puesto que el fin era la supervivencia. Así, reactivó sus relaciones con China, que se convirtió en el aliado político más importante, pero inició en el plano internacional una dicotomía de discurso y acción, al acercarse también a Estados Unidos; en 1991, además, se unió, junto con Corea del Sur, a la ONU, a pesar de todas las normas que implicaría su institucionalización, y ese mismo año firmó, de nuevo junto con Corea del Sur, la Declaración de Desnuclearización de la Península de Corea. Esto, sin embargo, se desarrolló aún dentro del marco de la Nordpolitik de Corea del Sur y, por otra parte, como lo considera Andrew Scobell (2004), China influyó al presionar a Kim II-sung para comenzar el diálogo ${ }^{7}$.

A partir de 2001, y con el cambio de prioridades de la política exterior norteamericana en su guerra contra el terrorismo, se inició un activismo en

\footnotetext{
7 No era la primera vez que Corea del Norte buscaba su propia seguridad bajo equilibrios de poder: ya en 1972 había alcanzado el diálogo intercoreano en términos de "no agresión" (Woodrow Wilson International Center for Scholars, 2012), pero este se rompió con el ingreso de Park Chung-hee como presidente de Corea del Sur.
} 
China para la búsqueda de estabilidad y de un tratamiento pacífico de la política militar de Corea del Norte, con el propósito de evitar un conflicto con Estados Unidos (McDermott, 2004). En 2003, China propuso una mesa de diálogo regional para tratar el tema de Corea del Norte, Ilamada La Plática de Seis Partes (The Six Party Talks on North Korea's Nuclear Program), con la que aseguraba que las acciones contra Corea del Norte no fueran unilaterales, sino que debían ser tratadas de forma multilateral entre China, Japón, Corea del Sur, Corea del Norte, Rusia y EE. UU. Esto podría entenderse como una forma de freno diplomático para cualquiera que intentara desestabilizar o atacar a Corea del Norte.

Sin embargo, las acciones de aislamiento de Corea del Norte se evidenciaron en sus constantes alejamientos de una política conciliadora: la provocación que significó su retiro del Tratado de No Proliferación Nuclear en 2003, el desarrollo de un programa nuclear, los constantes congelamientos de negociación en La Plática de Seis Partes, así como las pruebas nucleares de 2016 y 2017. En ese sentido, Corea del Norte representaría más un problema que un beneficio para China, dado su proyecto de desarrollo económico y comercial. Sin embargo, el apoyo diplomático, político y económico de China continúa fluyendo, sin importar las sanciones de la ONU y la condena de distintos países.

El programa nuclear ha sido para Corea del Norte un punto primordial de su política exterior y de sobrevivencia, pues consiste en lo que se denomina diplomacia militar, ya que utiliza la proliferación de armas para obtener concesiones económicas y diplomáticas a cambio de su moderación nuclear.

\section{El factor militar}

Durante la década de los noventa, Corea del Norte inició una escalada en sus acciones militares, sobre todo a través de su programa de misiles y su armamento nuclear, y con ello una diplomacia militar. El programa nuclear de Corea del Norte comenzó a finales de los años cincuenta, durante el contexto de la Guerra Fría y el conflicto regional; Rusia firmó un tratado para proveer asistencia técnica y se estableció el Centro de Investigación Nuclear de Corea del Norte. Esto constituyó la estrategia de defensa ante la escalada estadounidense de desarrollo nuclear en Taiwán y Corea del Sur (Szalontai y Radchenko, 2006). Aquella política de asistencia-defensa se extendió al desarrollo de armamento, a las relaciones comerciales y al apoyo económico, por parte de la URSS y de China.

Como se mencionó anteriormente, durante los años ochenta, los cambios en el contexto regional implantaron nuevas pautas diplomáticas y, en 1985, Corea del Norte firmó el Tratado de No Proliferación Nuclear, en una coyuntura que implicó un diálogo con Rusia, con EE. UU. e incluso con Corea del Sur, con el que había firmado, en 1991, el tratado de desnuclearización. No obstante, en 1993, Corea del Norte ame- 
nazó con su retiro del acuerdo, tras el informe del Organismo Internacional de Energía Atómica (OIEA), en el que se le acusaba de continuar con el programa de desarrollo nuclear; además, el país reveló su potencial armamentístico al realizar pruebas de lanzamiento de misiles en el mar de Japón. Durante esta situación de tensión, EE. UU. firmó un convenio con Corea de Norte, en 1994, para que frenara su programa nuclear en Yongbyon a cambio de concesiones: reactores de agua, entre otros (Carlin y Jones, 2008).

Durante la década de los noventa, Corea del Norte continuó con acciones de provocación, como el envío de tropas a la zona desmilitarizada entre las dos Coreas en 1996, el abandono de las Pláticas de Cuatro Partes ${ }^{8}$ y la prueba, en 1998, de misiles de mayor alcance al norte de Japón, entre otras. Empero, nada de lo anterior provocó un enfrentamiento que desestabilizara la región, gracias a la posición de China y EE. UU., países con los que mantenía un armisticio para contener su desarrollo nuclear a cambio de la ayuda que le proporcionaban.

En este periodo, Corea del Norte sostuvo un acercamiento constante con EE. UU., con lo cual negociaba apoyos. Así, en 1998 se acordó la visita de inspectores de energía atómica a sus instalaciones de Kumchang-ri, en 1999 y en el 2000. En 1999, Corea del Norte firmó un acuerdo para detener sus pruebas de misiles de largo alcance. Sin embargo, a partir de 2001, la situación de la península de Corea incrementó la inestabilidad, y las relaciones entre Corea del Norte y EE. UU. se tornaron conflictivas con el cambio de política exterior norteamericana y su lucha contra el terrorismo. Así, en enero de 2002, la administración Bush declaró a Corea del Norte como un Estado del eje del mal (Bush, 2002).

Como respuesta, Corea del Norte reveló que había reactivado sus instalaciones nucleares, y en 2003 se retiró del Tratado de No Proliferación Nuclear, así como del acuerdo de Desnuclearización de la Península de Corea. Ante esta situación de inestabilidad en la península, con la amenaza de una intervención estadounidense y su apoyo de defensa a Corea del Sur e incluso a Taiwán, fue China quien buscó un nuevo acercamiento multilateral a través de La Plática de Seis Partes (The Six Party Talks), que incluía a las dos Coreas, EE. UU., la misma China, Japón y Rusia. La iniciativa de China instaba a una garantía multilateral y evitaba así que otros Estados pasaran a una ofensiva militar de forma unilateral contra Corea del Norte, con lo cual también garantizaba su objetivo de mantener una estabilidad regional, el contexto necesario para el desarrollo regional, como lo declaró el ministro del exterior de China, Wang Yi (2013a).

8 En 1996, EE. UU. y Corea del Sur propusieron una mesa multilateral para tratar la presencia nuclear en la península. En esta participaron Corea del Norte y China, con el fin de crear un mecanismo permanente de estabilidad. 
Aunque este marco multilateral tuvo tres encuentros durante 2003 y 2004, en 2005, Corea del Norte declaró públicamente que producía armas nucleares para su autodefensa, y en 2006 realizó su primera prueba nuclear. Esta fue condenada por la ONU, la cual impuso sanciones colectivas en la resolución 1718, mientras que algunos Estados agregaron sanciones individuales. Con lo anterior, Corea del Norte estableció una nueva posición de poder nuclear regional, pero constituía una amenaza a toda la estructura del sistema internacional de proliferación de naciones con armamento nuclear. Asimismo, suspendió su participación en las pláticas multilaterales y condicionó su regreso a nuevas concesiones y programas de ayuda, lo cual se cumplió en 2007, gracias a una amplia intervención de China.

Esta forma de negociación, de entrar y salir de los procesos de diálogos a través de su diplomacia militar/nuclear, su único elemento de poder dentro del sistema regional, ha sido el comportamiento constante de Corea del Norte. En 2009 realizó su segunda prueba nuclear, así como pruebas de misiles de corto alcance; en 2010 tuvo un enfrentamiento militar con Corea del Sur en Yeonpyeong; en 2011 volvió a realizar pruebas de misiles; en 2012 orquestó el lanzamiento de un cohete de largo alcance, declarando que era el lanzamiento de un satélite; en 2013 tuvo lugar su tercera prueba nuclear; en 2014 realizó nuevos lanzamientos de misiles, que se estima ya eran transatlánticos; en 2015 declaró tener la capacidad de bombas de hidrógeno; en 2016 lanzó misiles que alcanzaron la zona económica exclusiva de Japón y efectuó dos pruebas nucleares más, y en 2017 probó un misil de largo alcance (Hwasong-15/13,000 km) y realizó su sexta prueba nuclear, que declaró como termonuclear.

Así, desde 2003, Corea del Norte ha incrementado de forma notable la frecuencia de pruebas balísticas y nucleares, como se puede observar en la figura 1 y en la tabla 1, elaboradas de acuerdo con los datos del Centro de Estudios Estratégicos e Internacionales (CSIS, su sigla en inglés), en su proyecto de defensa de misiles (Missile Defense Project). 


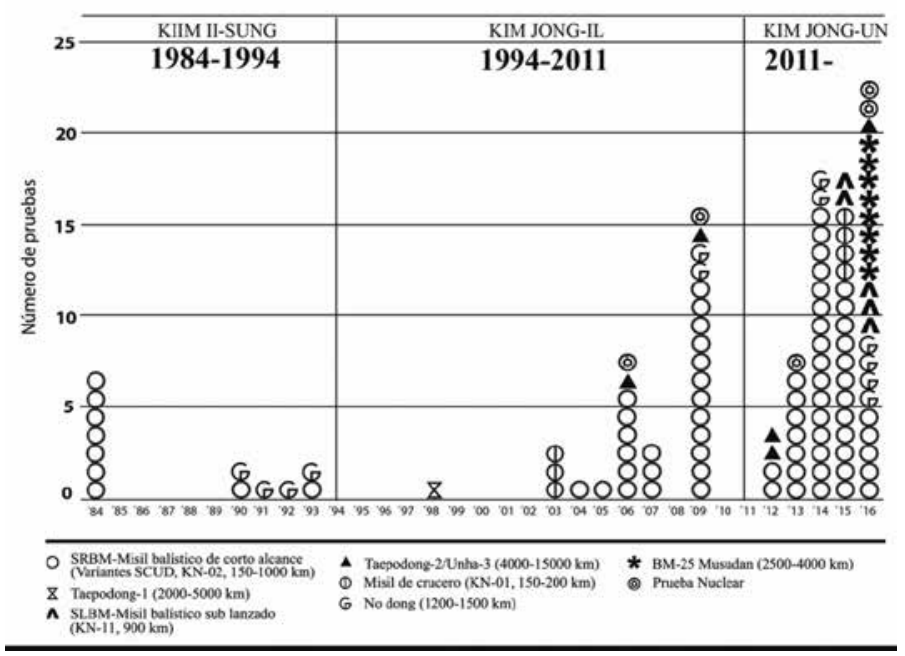

Figura 1. Pruebas nucleares y de misiles de Corea del Norte (1984-2017).

Fuente: George C. Marshall Institute (2017).

Tabla 1. Desarrollo de misiles de Corea del Norte

\begin{tabular}{|c|c|c|}
\hline Tipo de Misil & Rango & Estado \\
\hline Hwasong-15 & $8.500-13.000 \mathrm{~km}$ & En desarrollo \\
\hline Hwasong-14 & $10.000+\mathrm{km}$ & En desarrollo \\
\hline $\mathrm{KN}-08$ & $5.500-11.500 \mathrm{~km}$ & En desarrollo \\
\hline $\mathrm{KN}-14$ & $8.000-10.000 \mathrm{~km}$ & En desarrollo \\
\hline Hwasong-12 & $4.500 \mathrm{~km}$ & En desarrollo \\
\hline BM-25 Musudan & $2.500-4.000 \mathrm{~km}$ & En desarrollo \\
\hline KN-15 (Pukkuksong-2) & $1.200-2.000 \mathrm{~km}$ & En desarrollo \\
\hline $\mathrm{KN}-11$ & $1.200 \mathrm{~km}$ & En desarrollo \\
\hline KN-18 & $450+\mathrm{km}$ & En desarrollo \\
\hline No-Dong & $1.200-1.500 \mathrm{~km}$ & Operacional \\
\hline Scud-ER & $800-1.000 \mathrm{~km}$ & Operacional \\
\hline Hwasong-6 & $500 \mathrm{~km}$ & Operacional \\
\hline Hwasong-5 & $300 \mathrm{~km}$ & Operacional \\
\hline $\mathrm{KN}-02$ & $120-170 \mathrm{~km}$ & Operacional \\
\hline Taepodong-2 & $4.000-10.000 \mathrm{~km}$ & Operacional \\
\hline Taepodong-1 & $2.000-5.000 \mathrm{~km}$ & Obsoleto \\
\hline Kumsong-3 & $130-250 \mathrm{~km}$ & Posiblemente operacional \\
\hline KN-01 & $110-160 \mathrm{~km}$ & Operacional \\
\hline $\mathrm{KN}-09$ & $190 \mathrm{~km}$ & En desarrollo \\
\hline M1985/M1991 & $40-60 \mathrm{~km}$ & Operacional \\
\hline Koksan M1978 & $40-60 \mathrm{~km}$ & Operacional \\
\hline $\mathrm{KN}-06$ & $150 \mathrm{~km}$ & Operacional \\
\hline
\end{tabular}

Fuente: George C. Marshall Institute (2017). 
Con esta capacidad balística de ataque es claro que el alcance va más allá de la región de Asia, hacia otros Estados. Por eso, Corea del Norte se ha convertido en una amenaza al sistema internacional. En perspectiva, el país ha modificado la distribución de capacidades con respecto al poder militar a nivel regional, esto, aunque lo convierte en una amenaza real, también juega un papel defensivo para su supervivencia.

Lo anterior también ha causado que tanto Japón como Corea del Sur inicien propuestas de armamento, específicamente en los programas de defensa antimisiles, como fue anunciado desde 2006 (Consejo de Seguridad de Naciones Unidas, 2006). En 2014, Estados Unidos y Corea del Sur iniciaron pláticas para la instalación del sistema denominado Terminal High Altitude Area Defense (THAAD) y, en julio de 2016, Ilegaron a un acuerdo para desplegar tal sistema en suelo surcoreano, aunque fuera operado por las fuerzas militares norteamericanas, designadas en Corea del Sur (United States Forces Korea [USFK]) y dirigidas por el Comando del Pacífico (United States Pacific Command [USPACOM]) (U. S. Department of Defense, 2016). De esta forma, el mapa de relaciones de poder en la región se pone en juego bajo la amenaza de inestabilidad regional. Rusia declaró, en 2014, que el THAAD tan solo era la ampliación de la geografía de defensa antimisiles globales de EE. UU., lo que afecta la situación estratégica en la región y, además, puede provocar una carrera armamentista, incluso con alcances mayores: "En términos más generales, esto afectará negativamente a la estabilidad estratégica global" ${ }^{\prime \prime}$ (The Ministry of Foreign Affairs of the Russian Federation, 2014). En 2016, en una declaración conjunta, Rusia y China establecieron que el despliegue del THAAD perjudica gravemente los intereses estratégicos nacionales de seguridad de ambos Estados; plantean que "piensan de manera proactiva sobre las medidas que pueden fortalecer la coordinación entre China y Rusia frente a los factores negativos que surgen de la situación"10 (Ministry of Foreign Affairs, the People's Republic of China, 2016).

Para China, el crecimiento armamentista de Corea del Norte, por un lado, y el de Japón y Corea del Sur, por el otro, son una doble amenaza a su estabilidad. Primero a la seguridad nacional, ya que este crecimiento de arsenales militares está ubicado justo en sus fronteras, pero también porque implica un elemento de apoyo a Taiwán por parte de Japón y EE. UU., lo que afecta su legitimidad de poder ante la isla. En segundo lugar, está el ámbito económico-militar ante otros Estados, ya que debe encontrar un balance que no dañe su crecimiento económico y comercial al tiempo que limita la ampliación de poder en la región por parte de otros Estados, que

9 Traducción del autor del artículo.

10 Traducción del autor del artículo. 
podrían restringir su poder o llevarlo a una confrontación. Por ello, China mantiene una postura de disuasión, gracias a la utilización de instancias multilaterales, en las que la decisión de intervención tiene que pasar antes por una sucesión de negociaciones en las cuales puede intervenir, como lo es La Plática de Seis Partes, un grupo en el que es el principal promotor, o la ONU, en donde es miembro del Consejo de Seguridad.

\section{La relación económica}

Las relaciones económicas de Corea del Norte con otros Estados están estructuradas, en gran parte, en dos vertientes: la primera, mediante ayuda humanitaria o ayuda oficial al desarrollo que recibe, y la segunda que compete a las transacciones comerciales.
Con respecto a la ayuda oficial al desarrollo solo se puede deducir su alcance por la dificultad de obtener o estimar cifras en la relación con China y Corea del Sur; una estrategia de ayuda puede ser la inversión en proyectos de desarrollo, así como en bienes y especies, algo que no se contabiliza. Asimismo, este tipo de ayuda otorgada por otros Estados o Instituciones Internacionales se da primordialmente a través de productos: comida, medicinas y recursos energéticos, por ejemplo. A propósito, podemos encontrar que, de acuerdo con el Banco Mundial (World Bank, 2017), durante 2015, Corea del Norte recibió un poco más de US\$131 millones por parte del Comité de Ayuda al Desarrollo de la Organización para la Cooperación y el Desarrollo Económicos (OCDE, su sigla en inglés). Esto se puede observar en la figura 2.

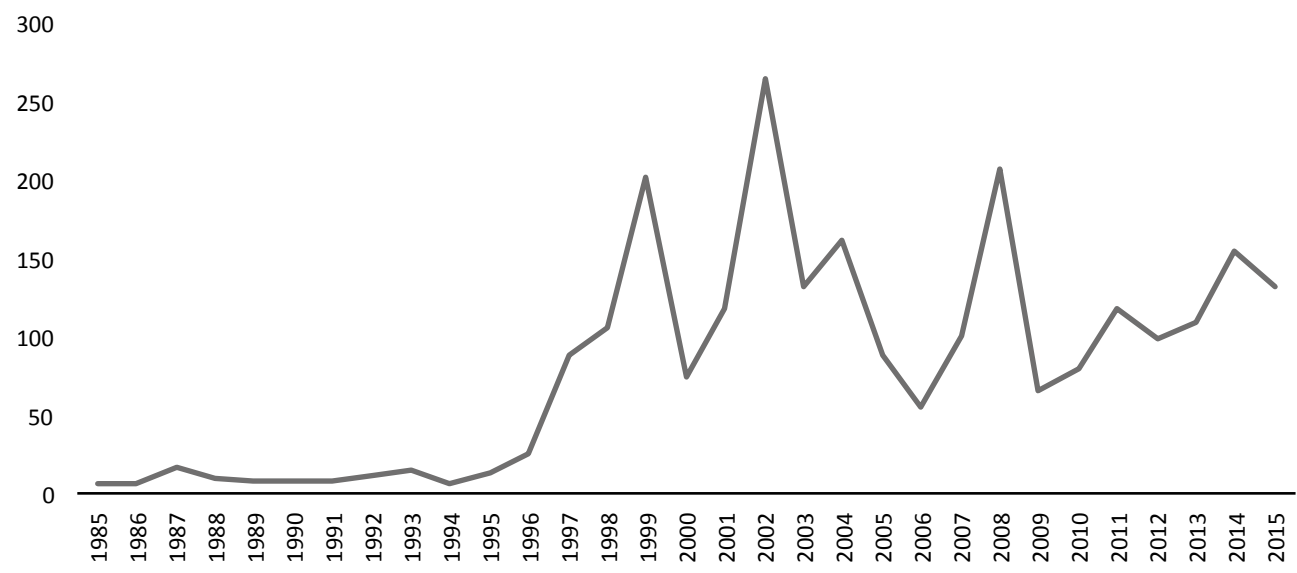

Figura 2. Ayuda oficial al desarrollo recibida por Corea del Norte, desde el año 1989 hasta 2014 (millones de dólares).

Fuente: elaboración del autor con base en la información del World Bank (2017). 
Como se observa, a continuación, en la figura 3, la ONU, por medio del Fondo Central para la Acción en Caso de Emergencias (CERF, su sigla en inglés), le ha otorgado a Corea del Norte más de US\$ 118 millones durante el periodo 2007-2016 (ONU/CERF, 2016). La mayoría de este capital se ha destinado a programas de salud, nutrición y sanidad.

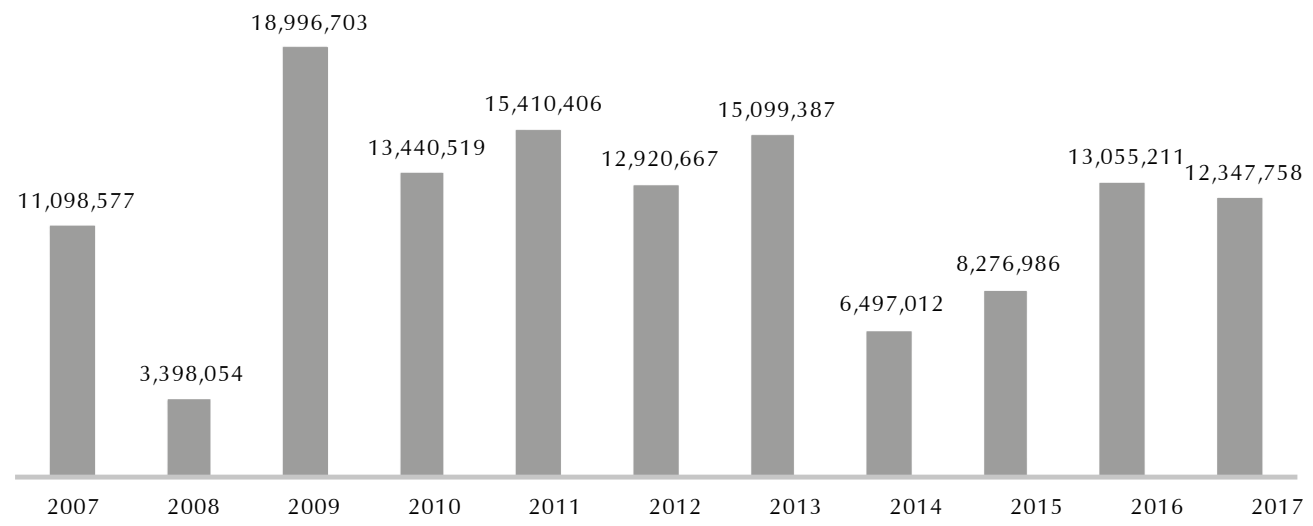

Figura 3. Apoyos del Fondo Central para la Acción en Casos de Emergencia recibidos por Corea del Norte, desde el año 2007 hasta 2017 (dólares).

Fuente: elaboración del autor con base en ONU/CERF (2017).

Los Estados que más brindan apoyo económico, tanto de forma institucional como a través de organizaciones no gubernamentales, a Corea del Norte son Corea del Sur y China. En el caso de Corea del Sur, la ayuda fue un incentivo para el desarrollo del país con miras a una posible negociación de paz y a una apertura entre las partes, principalmente a partir de la instauración del Ministerio de Reunificación de Corea. Sin embargo, a partir de 2008, con la llegada de Lee Myung- bak a la cabeza de la administración surcoreana y con el constante crecimiento de potencial de armamento de Corea del Norte, los apoyos han sido reducidos, como se verá en la figura 4. Se estima, entonces, que China es el mayor donador, pues tan solo en 2011 invirtió en varios proyectos de infraestructura (para el puerto de Dandong, muelles, carreteras y plantas de energía) un total de US\$ 9,1 mil millones (Wolf, Wang y Warner, 2013). 


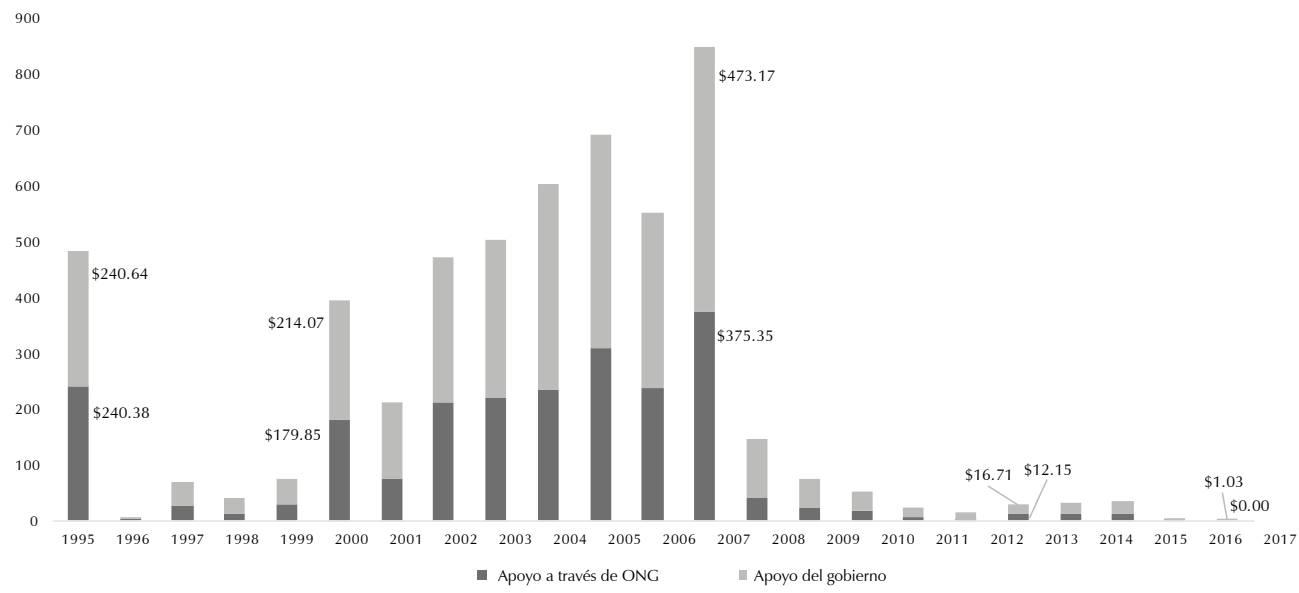

Figura 4. Ayuda humanitaria y préstamos de alimentos de Corea del Sur a Corea del Norte, desde el año 1995 hasta 2017 (millones de dólares) ${ }^{11}$.

Fuente: elaboración propia con base en la información del Ministry of Unification of Republic of Korea (2018).

Debido a la economía cerrada de Corea del Norte, sus transacciones suman en total apenas un poco más de us\$ 6.000 millones, como se podrá apreciar en la figura 5, lo que mantiene una balanza de pagos negativa. Esto puede resumir la naturaleza de sus relaciones comerciales.

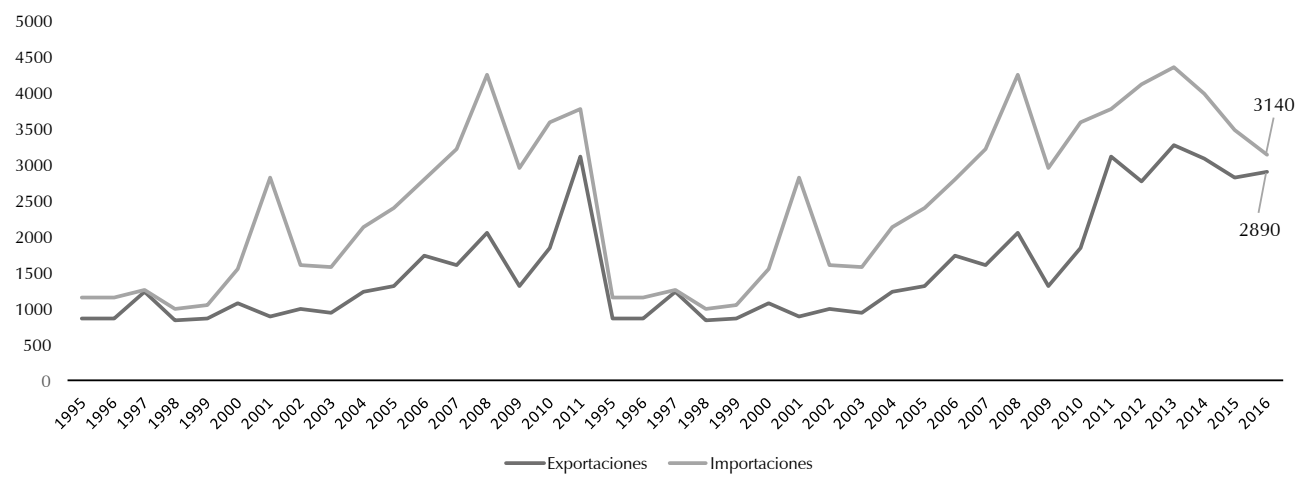

Figura 5. Comercio Exterior de Corea del Norte, desde el año 1989 hasta 2016 (millones de dólares).

Fuente: elaboración propia con base en la información sobre el periodo de 1995 a 2015 (MIT Observatory of Economic Complexity,2017) y la información del año 2016 (Harvard University Atlas of Economic Complexity, 2018).

11 La conversión del won surcoreano a dólares fue realizada por el autor con base a la tasa de intercambio del Banco Mundial, en el periodo de 1995 a 2016, mientras que para 2017 se utilizó la tasa de conversión reportada por el Departamento del Tesoro de Estados Unidos, correspondiente a diciembre de 2017. 
A partir de la caída de la URSS, las relaciones comerciales de Corea del Norte se diversificaron, puesto que entabló vínculos con otros Estados: pasó de tener cincuenta y ocho relaciones comerciales con otras economías, en el año 1989, a ciento treinta y cinco en 2007 y, posteriormente, ciento nueve en el año 2015. Sin embargo, el valor total de su comercio ha pasado de estar diversificado entre distintos socios a concentrarse en unos cuantos, especialmente en China, como se observará en la figura 6. Esto es consecuencia de sus acciones de aislamiento y de su agresiva política exterior. Por ello, Japón, por ejemplo, que estimuló relaciones comerciales con Corea del Norte durante finales de los años noventa, con el fin de acrecentar su relación de apertura multilateral, optó por cesar toda actividad comercial.

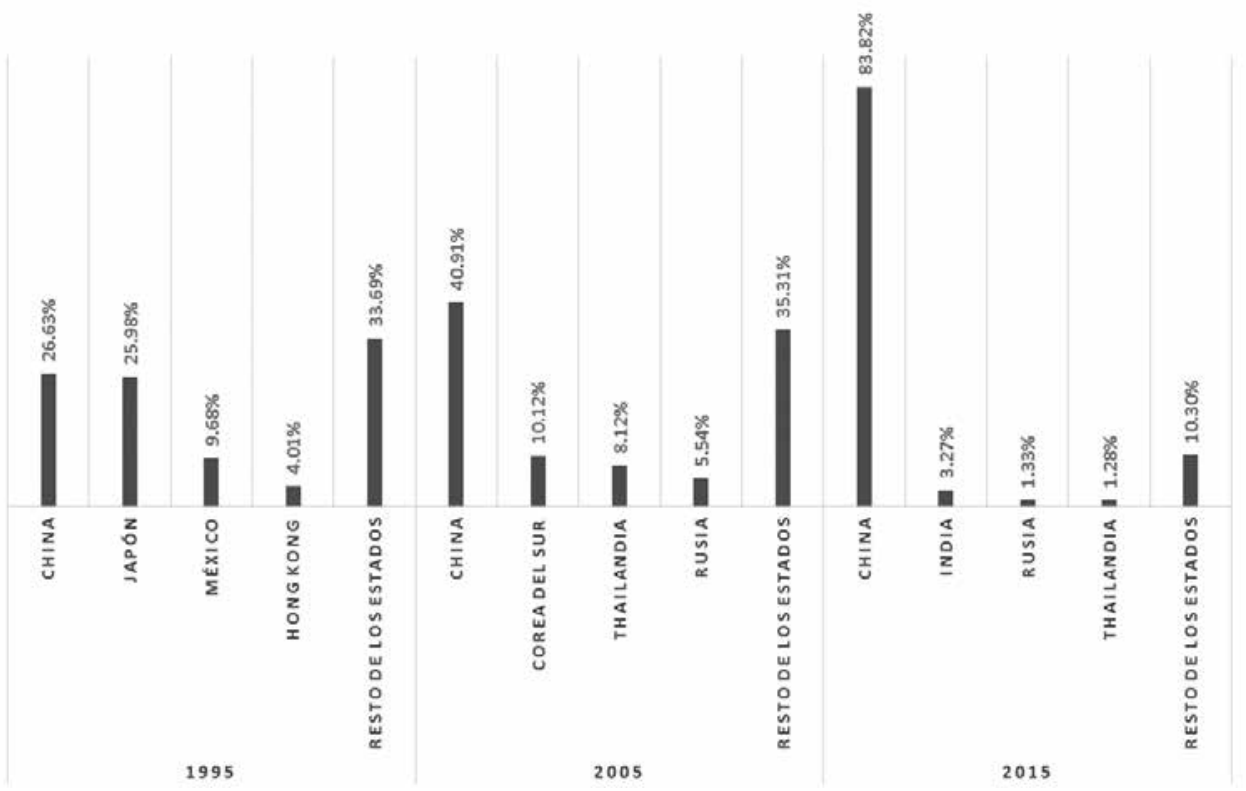

Figura 6. Principales socios comerciales de Corea del Norte. Distribución porcentual del total del comercio en los años 1995, 2005 y 2015.

Fuente: elaboración propia con base en la información del Observatory of Economic Complexity (2017). Los datos de Corea del Sur de los años 2005 y 2015 se han tomado de Ministry of Unification of Republic of Korea (2018).

El comercio exterior de Corea del Norte se ha concentrado en China, su principal socio, en tal proporción que podría pensarse en una relación de dependencia casi absoluta, con déficit en su balanza de pagos, como se puede observar en las figuras 8 y 9. 


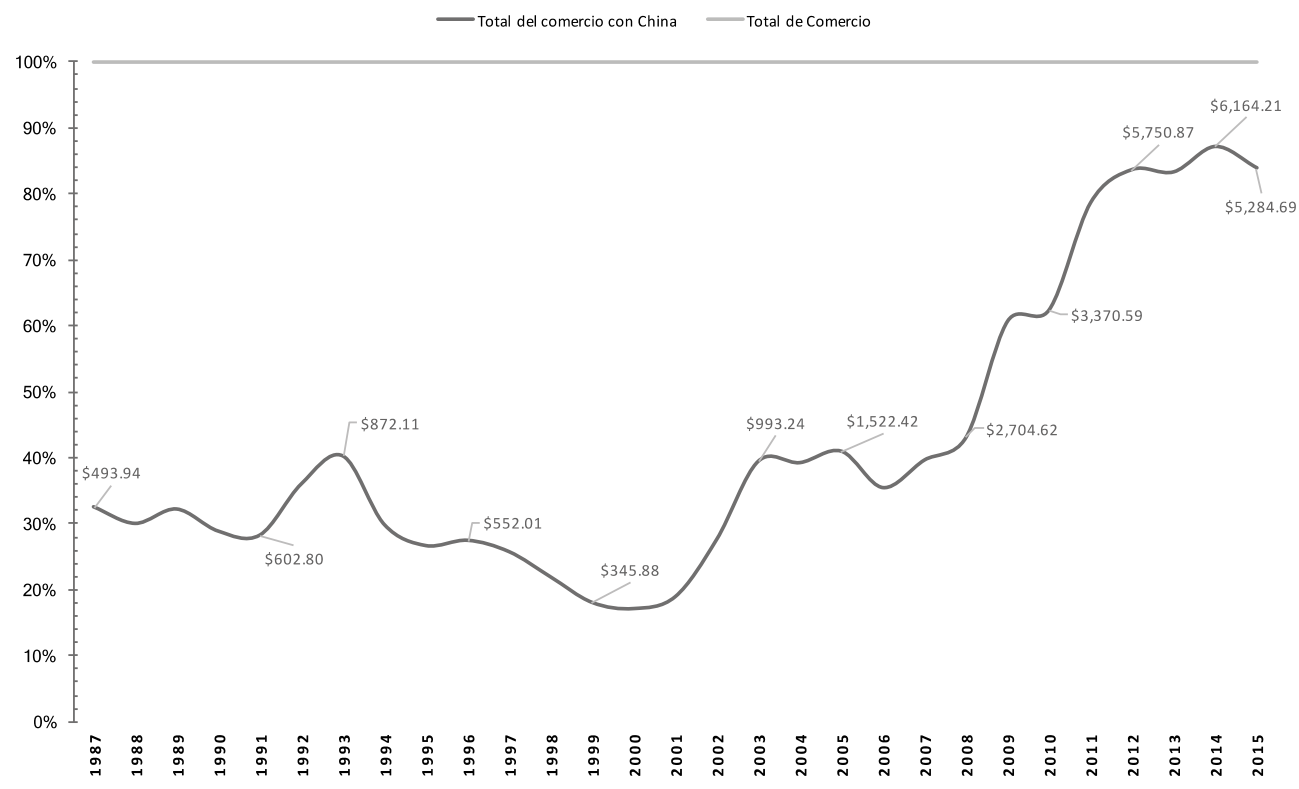

Figura 8. Relación comercial de China y Corea del Norte, respecto al total de comercio de Corea del Norte, durante el periodo comprendido entre 1987 y 2015 (millones de dólares).

Fuente: elaboración propia con base en la información del Observatory of Economic Complexity (2017).
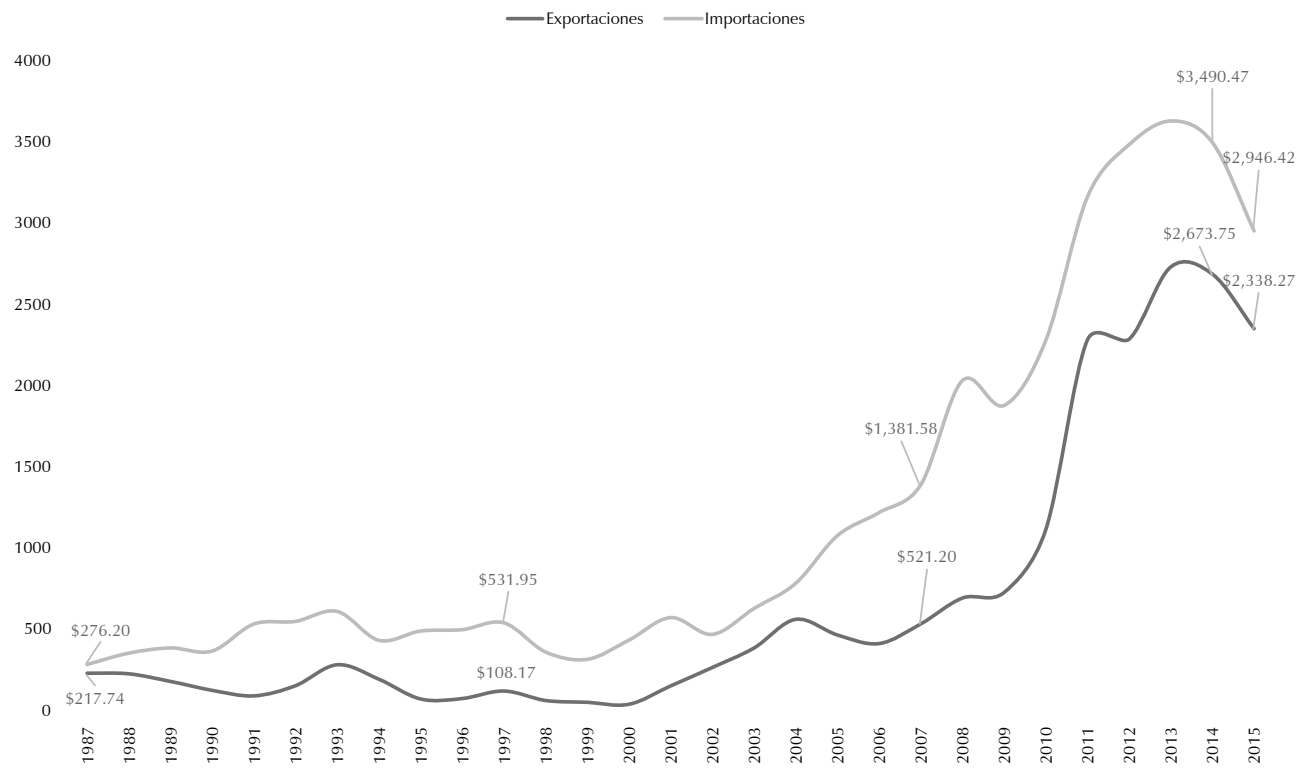

Figura 9. Balanza comercial de Corea del Norte con China, desde el año 1987 hasta 2015 (millones de dólares).

Fuente: elaboración propia con base en la información del Observatory of Economic Complexity (2017). 
En 2015, China representaba el 83.82\% del comercio total de Corea del Norte, un porcentaje muy superior al de sus otros socios comerciales: la India, que sumaba solo el $3.27 \%$, Rusia, que representaba el $1.33 \%$, y Tailandia que apenas contabilizaba el $1.28 \%$ (Observatory of Economic Complexity, 2016). Por su parte, Corea del Sur, a partir de 2011, dismi- nuyó radicalmente el porcentaje de su comercio con Corea del Norte: se pasó de un total de US\$ 435 millones en 2010 a tan sólo US\$ 4 millones en 2011. El intercambio económico se mantuvo, sin embargo, debido a proyectos de cooperación industrial, de la zona económica especial intercoreana y del turismo, como se puede observar en la figura 10 .

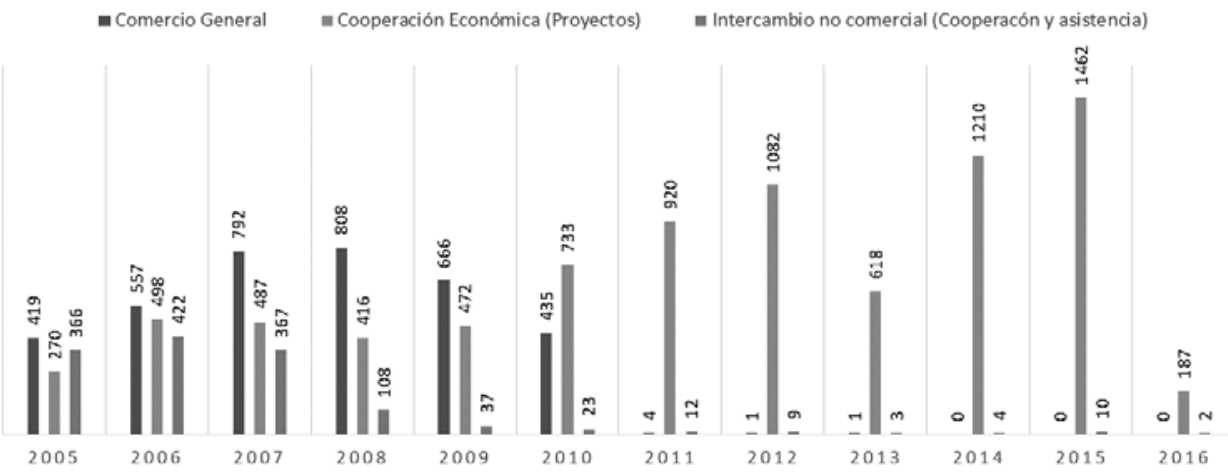

Figura 10. Valor del comercio Intercoreano por tipo de actividad, desde el año 2005 hasta el 2016 (millones de dólares).

Fuente: elaboración propia con base en la información del Ministry of Unification of Republic of Korea (2018).

Estas cifras reflejan la importancia que para Corea del Norte tiene la transferencia de recursos de China, principalmente, y de Corea del Sur para su subsistencia.

\section{Multilateralismo}

De forma unilateral, los principales actores internacionales de la zona del este asiático (Corea del Sur, China, Japón, Estados Unidos y Rusia) han negociado con Corea del Norte sobre sus prácticas armamentistas y su apertura política. Sin embargo, estos intentos de diálogo han fallado. Lo que han buscado aquellos Estados es un multilateralismo, pues para lograr sus intereses necesitan la estabilidad de la península de Corea.

En 1994, Rusia propuso la creación de una mesa de diálogo para participar junto con otros siete actores involucrados: Estados Unidos, Japón, China, las dos Coreas, el Organismo Internacional de Energía Atómica (OIEA) y el Secretario General de la ONU. No obs- 
tante, esta propuesta fue rechazada por Corea del Norte, que se encontraba en disputa con Rusia por la modificación a su acuerdo de 1961, sobre la posibilidad de ayuda militar en caso de ataque, así como por la expansión de sus relaciones, mediante el acercamiento Con EE. UU. y Corea del Sur (Radchenko, 2015).

En 1997, tras las pláticas fallidas entre EE. UU. y Corea del Norte para modificar el armisticio de 1953 por un tratado de paz, se inició otro intento, ahora dirigido por Estados Unidos y Corea del Sur, que propusieron un diálogo multilateral formal conocido como las Pláticas de Cuatro Partes. Este tenía como participantes a Corea del Norte y Corea del Sur, Estados Unidos y China, y dejaba a Rusia, un actor regional, de lado. El intento de negociación estaba auspiciado por EE. UU., que mantenía conversaciones con Corea del Norte desde 1994, por medio del programa del Acuerdo de Desarrollo de Energía en la Península de Corea (KEDO, por su sigla en inglés), en el que participaban Corea del Sur y Japón. Además, debemos sumar las reuniones sobre los programas de misiles, que iniciaron en 1996.

Pero las Pláticas de Cuatro Partes también fueron ineficientes a la hora de resolver el conflicto. Aunque los Estados compartían un interés común: lograr la estabilidad en la península de Corea, las propuestas individuales sobre cómo lograr dicha estabilidad eran distintas. Corea del Norte había establecido directrices para un acercamiento unilateral con EE. UU., incluso en sus comunicados mencionaba que solo podría llegarse a un acuerdo de paz por medio del diálogo directo entre los generales de Estados Unidos y de Corea del Norte (Organización de las Naciones Unidas/Consejo de Seguridad, 1997). De este modo, Corea del Norte aseguraba su supervivencia al evitar la participación de Corea del Sur. Por el contrario, el presidente Clinton había declarado como objetivo de las pláticas el logro de los diálogos intercoreanos, y negaba así toda posibilidad de negociación unilateral (Clinton, 1996), lo cual manifestaba su tendencia hacia la unificación de las dos Coreas.

Para Corea del Sur, el acercamiento de Estados Unidos significaba acceder a pláticas directas con Pyongyang, algo que su entonces mandatario, Kim Young- sam, había buscado desde el inicio de su administración, aunque sin una intención de reunificación, sino de lograr, más bien, relaciones que fortalecieran un interés común de paz. Dicho acercamiento continuó con su sucesor, Kim Dae-jung, aunque ya con una clara propuesta de unificación (Ministry of Unification of Republic of Korea, 2003). Por último, para China era importante lograr un acuerdo pacífico en la península que implicara un balance entre las dos Coreas. De acuerdo con Jing-yi (2016), China había pasado de apoyar una reunificación confederada a un entendimiento compartido sin desarticulación de ninguna de las dos Coreas.

Como todos los participantes tenían distintos acercamientos, y estaba de 
por medio el asunto más importante: la diferencia entre las dos Coreas, el resultado fue la imposibilidad de lograr sus objetivos individuales, por lo que, en 1998, Corea del Norte suspendió su participación en las Pláticas de Cuatro Partes y lanzó un misil, con el fin de declarar que tenía la capacidad suficiente para alcanzar el territorio de Japón. A causa de esto, Japón y Corea del Sur declararon a Corea del Norte como una amenaza creciente a su seguridad. En este momento, el gobierno de Japón comunicó su capacidad para construir armamento, lo que provocó en la región un dilema de seguridad armamentista.

En 2002, tras el informe de la CIA sobre la actividad de enriquecimiento de uranio por parte de Corea del Norte y la política antiterrorista de EE. UU., la situación en la península se agravó. En un comunicado de octubre de ese año, Corea del Norte buscó la firma de un pacto de no agresión con Estados Unidos, pero este no se logró. Así que Corea del Norte, siguiendo su diplomacia militar, anunció, en 2003, la reactivación de instalaciones nucleares y su salida del Tratado de No proliferación de Armas Nucleares, pero manifestó, además, que si EE. UU. abandonaba su política hostil estaba dispuesto a negociar. (Ministry of Unification of Republic of Korea, 2003).

En este contexto, en abril de 2003, se inició en Beijing una ronda de pláticas multilaterales conocida como las Pláticas de Tres Partes. En esta participaban China, Estados Unidos y Corea del Norte. De acuerdo con lo que dijo Wang Yi (2003), Viceministro de Asuntos Exteriores de China, en su conferencia de prensa, Corea del Norte propuso realizar pláticas multilaterales con otros participantes, propuesta apoyada por EE. UU. con el fin de incluir a Japón, Corea del Sur y Rusia (Bush, 2013). Así, se inició La Plática de Seis Partes. Para China era vital iniciar un proceso de diálogo con el propósito de evitar un ataque contra Corea del Norte, como lo declaró el Viceprimer Ministro, Wang Yi, pues la estabilidad de la península afectaba directamente los intereses del país. De ahí que su prioridad fuera una península libre de armas nucleares; para lograrla, China debía atender todo lo relacionado con la seguridad de Corea del Norte (YI, 2003).

Al igual que lo sucedido con las pláticas de Cuatro Partes, las pláticas iniciadas en 2003 sólo calmaron la situación hasta 2008, y en 2009, cuando Corea del Norte lanzó su segunda prueba nuclear, Estados Unidos, Japón y Corea del Sur desestimaron avanzar en los diálogos. De nuevo, puede entenderse que la imposibilidad de hallar una solución residía en la divergencia de los intereses de los Estados. De acuerdo con Park (2005), pese a que las negociaciones tenían como tema central el desarrollo del programa nuclear, existían otros temas fundamentales con relación a la crisis que debían tratarse y resolverse en conjunto. Sin embargo, cada Estado tenía distintas prioridades respecto a estos asuntos, razón por la que no se podía avanzar en las 
negociaciones, tal como se observa en la tabla 2. A lo anterior debemos sumar el hecho de que siempre existió una confrontación entre las intenciones de EE. UU. y de Corea del Norte, pues el primer país establecía que el programa de desarrollo nuclear debía parar si se quería negociar, mientras que el segundo promulgó que las negociaciones debían tratar otros temas que garantizaran su seguridad, y que el desarrollo de armas nucleares era un asunto de autodefensa para proteger su supervivencia (China Daily, 2003).

Tabla 2. Temas principales y su prioridad para los Estados involucrados en La Plática de Seis Partes

\begin{tabular}{|l|l|l|l|l|}
\hline & \multicolumn{1}{|c|}{$\begin{array}{c}\text { Proliferación } \\
\text { nuclear }\end{array}$} & \multicolumn{1}{|c|}{ Refugiados } & Misiles balísticos & $\begin{array}{c}\text { Reunificación de } \\
\text { la península de } \\
\text { Corea }\end{array}$ \\
\hline Estados Unidos & Crítico & Baja & Crítico & Alta \\
\hline China & Crítico & Crítico & Media & Alta \\
\hline Corea del Norte & Crítico & Crítico & Baja & Crítico \\
\hline Japón & Crítico & Baja & Crítico & Media \\
\hline Corea del Sur & Media & Alta & Baja & Crítico \\
\hline Rusia & Media & Baja & Baja & Media \\
\hline
\end{tabular}

Fuente: copiado del documento "Inside Multilateralism: The Six-Party Talks. The Washington Quarterly", de Park (2005).

Durante los últimos años, debido a la amenaza externa que representó el incremento de armamento y las pruebas nucleares de Corea del Norte, en especial desde el año 2014 hasta 2017, China ha intentado sin éxito que se reanude La Plática de Seis Partes, mientras que Estados Unidos y Japón no muestran interés alguno en retomarlas. Por su parte, Corea del Sur propuso, en 2016, una Plática de Cinco Partes, que dejaba de lado a Corea del Norte (Reuters, 2016), pero China y Rusia mostraron su desacuerdo con esta propuesta.

La posición de China es seguir con diálogos multilaterales en mesas de tres, cuatro o cinco partes, que puedan llevar a reanudar La Plática de Seis Par- tes; el país mantiene su propuesta de desnuclearización de la península, así como el paso del armisticio hacia un acuerdo de paz, pero quiere asegurar, mediante un acuerdo, la supervivencia y existencia de Corea del Norte $(\mathrm{Yi}$, 2016). Como lo estableció el Ministro de Relaciones Exteriores de China, Wang Yi (2016), las partes involucradas deben actuar con moderación y abstenerse de agravar la tensión, pues la situación se puede salir de control y terminar en un desastre para todas las partes. China no se sentará a ver daños injustificados a sus intereses de seguridad.

Otro foro multilateral que se ha utilizado como vía de trabajo es la ONU, específicamente el Consejo de Segu- 
ridad, que representa parte del institucionalismo del sistema. Recordemos cuando, en 1993, se instauró el tema de la proliferación de armas nucleares y la desnuclearización de la península de Corea como un asunto prioritario (ONU/Consejo de Seguridad, 1993). Este foro difiere de los anteriores por su apertura, ya que en sus discusiones y decisiones se tienen en cuenta un gran número de participantes regionales y no regionales, aunque se excluya la participación de Corea del Norte. Por su estructura multitemática se han puesto sobre la mesa asuntos como el armamento, el desarrollo nuclear y los derechos humanos, y se han impuesto sanciones a Corea del Norte. No obstante, todos estos esfuerzos han sido ineficientes para frenar el crecimiento armamentista del país. Como lo expresó, en 2016, el Secretario General de dicha institución, Ban Ki-moon: después de treinta y tres años, y seis resoluciones de sanciones no se ha podido resolver la situación (ONU/Consejo de Seguridad, 2016).

Ahora bien, tanto China como Rusia, que son miembros permanentes del Consejo de Seguridad, han sido reconocidos por querer adoptar medidas laxas en contra de Corea del Norte; en 2006, en la reunión para la adopción de la resolución 1695, el representante del gobierno de Japón acusó de forma directa a China y Rusia de proponer medidas débiles e insuficientes para lidiar con la situación (ONU/Consejo de Seguridad, 2006). Asimismo, en 2009, en la reunión para asentar la resolución 1879, en la que se extendían las san- ciones hacia todo comercio y transacciones financieras, tanto China como Rusia consideraron que las revisiones de embarques serían solo para aquellos con evidencias de cargamento destinado a los programas de desarrollo de misiles y de tecnología nuclear, y que únicamente se debía restringir el comercio, cuando se tratase de bienes de lujo; todo lo anterior debía hacerse sin uso de fuerza militar y respetando la soberanía, la integridad territorial y las preocupaciones legítimas de seguridad de Corea del Norte, así como su desarrollo económico (ONU/Consejo de Seguridad, 2009).

Otro factor a considerar es que los intereses siguen siendo diferentes para los actores involucrados. Si bien se trata de un foro más amplio, las partes implicadas en la problemática regional mantienen sus propósitos individuales; esto atenta contra el equilibrio de intereses. En 2016, mediante la resolución 2321, se acordaron sanciones más severas que afecten las exportaciones básicas, la actividad diplomática, y también se planteó la posibilidad de hacer una revisión total del comercio aéreo y marino, proveniente de Corea del Norte y con destino a esta. En la reunión de aprobación (ONU/Consejo de Seguridad, 2016), el representante de EE. UU. fijo su posición: enmarcó la amenaza que representa el armamento de Corea del Norte, no solo para su gobierno sino para el total del sistema, motivo por el que, según este, la ONU y sus miembros debían imponer medidas estrictas. La posición de Rusia, en cambio, fue una referencia directa al dile- 
ma de seguridad que se podría generar, si se incrementaba la presencia militar de otros Estados externos a la región. Con referencia al THAAD, concluyó que "un país no puede alcanzar su seguridad a largo plazo si trata de obtenerla a expensas de la seguridad de otros" (ONU, Consejo de Seguridad, 2016, p. $8)^{12}$. Esto se remitía también a la amenaza armamentista. China al igual que Rusia estimó el dilema de seguridad y el asunto del THAAD, pero estableció su posición con relación a la seguridad estratégica, que involucra la distribución del balance regional. Por último, Corea del Sur concentró su interés en la reunificación, pues, para el país, el régimen norcoreano estaba enlazado a un asunto de seguridad, de identidad nacional y de división de la nación.

\section{Conclusión}

Corea del Norte es un actor primordial para China, desde el punto de vista político y geoestratégico. Durante la guerra fría, el apoyo que brindaba China al Estado norcoreano simbolizó una afinidad ideológica —en la que la continua existencia de un Estado representaba una forma de legitimación del régimen para el otro, lo que garantizaba la reafirmación del PCCh (Scobell, 2004)—, pero también respondía a un gran interés en la seguridad.

Aunque Corea del Norte parezca un estado satélite de China, la realidad es que su estabilidad representa para
China la estabilidad en toda la península de Corea, lo cual es crucial para la seguridad territorial, política y económica del país. En el aspecto geopolítico comparten 1368 kilómetros de frontera, así que una confrontación armada con Corea del Norte sería una amenaza al territorio chino e implicaría un debilitamiento a su proceso de desarrollo. Asimismo, la caída del régimen norcoreano y su ocupación por parte de Corea del Sur implicaría, principalmente, la pérdida de la península de Corea con el posicionamiento militar y político de EE. UU. Esto amenazaría el poder regional de China, abriendo la puerta a nuevas amenazas como la reafirmación de identidades separatistas como la de Taiwán.

Ahora bien, la insistente agresividad de la política norcoreana, con su búsqueda de seguridad a través del armamentismo, también es una amenaza para China. Lo anterior ha provocado que sus vecinos, Japón y Corea del Sur, desarrollen su propia capacidad defensiva al sentirse amenazados, e implica, a su vez, un potencial armamentista para los fines de protección a Taiwán. Es preciso señalar, por otra parte, que el comportamiento de Corea del Norte tuvo un cambio a partir de 2011 con la llegada al poder de Kim Jong-un. Con su llegada al poder, se establecieron como líneas prioritarias el progreso económico y armamentista. Esta segunda prioridad es lo que ha impactado en mayor medida

12 Original en inglés: "A country cannot possibly achieve lasting long-term security if it tries to build it at the expense of the security of other States". 
en el tema de seguridad, a causa del desarrollo acelerado de armas y de las constantes pruebas balísticas. En términos políticos, la situación ha llevado al país a separarse de las propuestas multilaterales y a una limitada apertura a la negociación.

Conforme Corea del Norte incrementa su potencial armamentista se complica el escenario de China para mantener al resto de los Estados de la región, así como a Estados Unidos, en una posición pasiva, que evite cambios en el balance de poder y en las dinámicas de relaciones en la región. En este sentido, el apoyo de China a Corea del Norte tiene intereses con base en su propia seguridad.

China, en su búsqueda de evitar el colapso del régimen norcoreano o un alejamiento de este que conduzca a una configuración negativa de la balanza de poder en la región, se ha acercado a trabajar con otros Estados de forma individual y colectiva. De forma colectiva, ha trabajado a través de distintas mesas de diálogo multilaterales, en las que ha sostenido que no puede existir una intervención bilateral que provoque una confrontación, pues las consecuencias serían multilaterales. En ese sentido, la solución debe plantearse también de forma multilateral, a través de la alineación de intereses y, por ende, del compromiso en mantener la institucionalización.

Sin embargo, los intentos de construcción de dicha estructura no han funcionado, debido a los distintos in- tereses de los Estados, lo cual ha fracturado la institucionalización de las mesas de diálogo. Esto se evidencia en los comportamientos y acciones de los participantes. Por otra parte, con relación al trabajo individualizado, Estados Unidos, Rusia y Corea del Sur han sido los actores con los que China ha logrado un mejor diálogo, aunque para EE. UU. y para Rusia, el problema norcoreano se asocie a una cuestión de intereses geopolíticos. Para Corea del Sur implica también una cuestión de intereses internos, por lo que comparte la misma visión que China: la estabilidad depende del fortalecimiento del Estado norcoreano para sus reformas internas, del acercamiento intercoreano, e incluso de la posible reunificación de Corea. Para China, la reunificación y desnuclearización de la península de Corea concierne a sus intereses de poder regional, por lo que debe realizarse con él como principal mediador y sin la diligencia de EE. UU.

\section{Referencias}

Banco Mundial. (s. f.). Data Bank, Net official development assistance and official aid received. Korea 19192014. Recuperado de https://data. worldbank.org/indicator/DT.ODA. ALLD.CD?end $=2014 \&$ locations $=$ KP\&start $=19 \% 2078 \&$ view $=$ chart

Bush, G. (29 de enero de 2002). President Delivers State of the Union Address. Washington D.C.: The White House. Recuperado de https://georgewbushwhitehouse.archives.gov/news/releases/2002/01/20020129-11.html 
Bush, G. (14 de mayo de 2003). Joint Statement Between the United States of America and the Republic of Korea: Common Values, Principles, and Strategy. Recuperado de https://www.presidency.ucsb.edu/documents/ joint-statement-between-the-united-states-america-and-the-republic-korea-common-values

Buzan, B., Wæver, O. y de Wilde, J. (1998). Security: A New Framework for Analysis. Londres: Lynne Rienner.

Carlin, R. y Lewis, J. (2008). Negotiating with North Korea: 1992-2007. Stanford: Center for International Security and Cooperation, Stanford University.

Cartwright, M. (30 de noviembre de 2016). Ancient Korean \& Chinese Relations. Ancient History Encyclopedia. Recuperado de https://www. ancient.eu/article/984/ancient-korean--chinese-relations/

Central Intelligence Group. (3 de enero de 1947). The Situation in Korea. Washington D. C.: Central Intelligence Agency (CIA). Recuperado de https://www.cia.gov/library/readingroom/docs/DOC_0000256989. pdf

Clinton, W. J. (16 de abril de 1996). The President's News Conference With President Kim Young-sam of South Korea in Cheju. Recuperado de http://www.presidency.ucsb. $\mathrm{edu} / \mathrm{ws} /$ ?pid $=52677$

Consejo de Seguridad de las Naciones Unidas. (11 de mayo de 1993).
Resolution 825 adopted by the Security Council at its $3212^{\text {th }}$ meeting. Recuperado de http://www. un.org/en/ga/search/view_doc. asp?symbol=S/RES/825(1993)

Consejo de Seguridad de las Naciones Unidas. (21 de julio de 1997). Carta dirigida al presidente del Consejo de Seguridad por el encargado de negocios interino de la misión permanente de la República Popular Democrática de Corea ante las Naciones Unidas. Recuperado de http://repository.un.org/ bitstream/handle/11176/39819/ S $\quad \begin{array}{lllllllll}1 & 9 & 9 & 7 & 5 & 6 & 6 & \mathrm{E} & \mathrm{S}\end{array}$. 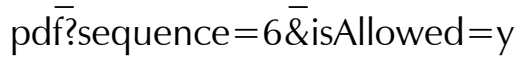

Consejo de Seguridad de las Naciones Unidas. (15 de julio de 2006). $5490^{\text {th }}$ meeting of the Security Council. Recuperado de http://www. un.org/en/ga/search/view_doc. asp? symbol=S/PV.5490

Consejo de Seguridad de las Naciones Unidas. (14 de octubre de 2006). 5551st meeting of the Security Council. Recuperado de http://www. un.org/en/ga/search/view_doc. asp?symbol=S/PV.5551

Consejo de Seguridad de las Naciones Unidas. (12 de junio de 2009). 6141st meeting of the Security Council. Recuperado de http://www. un.org/en/ga/search/view_doc. asp?symbol=S/PV.6141

Consejo de Seguridad de las Naciones Unidas. (30 de noviembre de 2016). Resolution 2321 adopted by the Security Council at its 7821st meeting. Recuperado de http://www. 
un.org/en/ga/search/view_doc. asp?symbol =S/RES/2321(2016)

Comment by the Russian Ministry of Foreign Affairs regarding the possibility of deployment of THAAD US air defences in the territory of the Republic of Korea. (24 de julio de 2014). The Ministry of Foreign Affairs of the Russian Federation. Recuperado de http://www.mid.ru/ en/foreign_policy/news/-/asset_publisher/cKNonkJE02Bw/content/ id/676887

Fondo Central para la Acción en Casos de Emergencia de las Naciones Unidas (CERF). (2017). CERF Grants by Country 2017. Recuperado de http://www.unocha.org/cerf/ cerf-worldwide/allocations-country/2017

Herz, J. (1950). Idealist Internationalism and the Security Dilemma. World Politics, 2(2), 157-180. doi:10.2307/2009187

Jing-yi, J. (2016). Simultaneous Promotion of Denuclearization and the Peace Treaty on the Korea Peninsula. 6.15 and Sunshine Policy, (págs. 29-48). Seoul.

Joint Statement Following Discussions With Leaders of the People's Republic of China. (27 de febrero de 1972). Office of the Historian. Recuperado de https://history.state. gov/historicaldocuments/frus196976v17/d203

Korean Statistical Information Service. (15 de 11 de 2016). Corea del Norte y las estadísticas internacionales. Obtenido de Norte-Sur Fondo de
Cooperación: http://kosis.kr/statHt$\mathrm{ml} /$ statHtml.do?orgld = 101 \&tblld = DT_1ZGAC\&conn_path $=12$

León, J. (2005). Cooperación y conflicto en la cuenca del Pacífico. México D. F.: Universidad Autónoma Metropolitana.

McDermott, R. (2004). Countering Global Terrorism: Developing the Antiterrorist Capabilities of the Central Asian Militaries. Carlisle, PA: Strategic Studies Institute.

Mearsheimer, J. (1994). The False Promise of International Institutions. International Security, 19(3), 5-49. doi:10.2307/2539078

Ministry of Foreign Affairs of the People's Republic of China. (29 de julio de 2016). China and Russia Hold the 4th Consultation on Northeast Asia Security. MFA News. Recuperado de http://www.fmprc. gov.cn/mfa_eng/wjbxw/t1386345. shtml

Ministry of Unification Republic of Korea. (2018). South-North Relations, Data \& Statistics. Recuperado de http://www.unikorea.go.kr/eng unikorea/relations/statistics/traffic/

Ministry of Unification Republic of Korea. (2014). Understanding North Korea. Seoul: Institute for Unification Education.

Ministry of Unification Republic of Korea. (2003). Five Years of the Kim Dae-jung Administration Promoting Peace and Cooperation. Seoul: Ministry of Unification. Recuperado de https://www.ncnk.org/ 
sites/default/files/content/resources/ publications/KDJ_DPRK_Inter_Korean_Highlights_1998_2003.pdf

Missile Defense Project. (14 de junio de 2018) Missiles of North Korea. Missile Threat. Center for Strategic and International Studies. Recuperado de https://missilethreat.csis. org/country/dprk/

MIT Observatory of Economic Complexity. (s.f.). North Korea. Recuperado de http://atlas.media.mit.edu/ en/profile/country/prk/

Park, J. S. (2005). Inside Multilateralism: The Six-Party Talks. The Washington Quarterly, 28(4), 73-91.

Quansheng, Z. (1996). Interpreting Chinese Foreign Policy: The MicroMacro Linkage Approach. Nueva York: Oxford University Press.

Radchenko, S. (13 de febrero de 2015). Russia's Policy in the RunUp to the First North Korean Nuclear Crisis, 1991-1993. Nuclear Ploriferation International History Project Working Paper 4. Recuperado de https://www.wilsoncenter. org/publication/russias-policy-therun-to-the-first-north-korean-nuclear-crisis-1991-1993

Republic of Korea and the United States Make Alliance Decision to Deploy THAAD to Korea. (7 de julio de 2016). U.S. Department of Defense. Recuperado de https://dod.defense.gov/News/News-Releases/NewsRelease-View/Article/831178/ republic-of-korea-and-the-unitedstates-make-alliance-decision-todeploy-thaad/
Ryutaro, H. (28 de agosto de 1997). Speech by Prime Minister Ryutaro Hashimoto. Seeking a New Foreign Policy Toward China. Tokio: Ministry of Foreign Affairs of Japan. Recuperado de https://www.mofa.go.jp/ region/asia-paci/china/seeking.html

Sanford, D. (1993). Rok's Nordpolitik: Revisited. The Journal of East Asian Affairs, 7(1), 1-31.

Scobell, A. (marzo, 2004). China and North Korea: From Comrades-inArms to Allies at Arm's Length. Carlisle, PA: Strategic Studies Institute. Recuperado de https://www. globalsecurity.org/military/library/ report/2004/ssi_scobell.pdf

Seth, M. (2010). A History of Korea: From Antiquity to the Present. Lanham, MD: Rowman \& Littlefield Publishers.

Shin, J. (2012). DPRK Perspectives on Korean Reunification after the July 4th Joint Communiqué. NKIDP eDossier 10. Recuperado de https:// www.wilsoncenter.org/publication/ dprk-perspectives-korean-reunification-after-the-july-4th-joint-communique

Song, C. (18 de diciembre de 2012). Commemorative Museum of the War to Resist U.S. Aggression and Aid North Korea. China Highlights. Recuperado de http://www. chinahighlights.com/dandong/ attraction/commemorative-museum-of-thewar-to-resist-u.s.-aggression-and-aid-north-korea.htm

South Korea's Park seeks 5party talks on North's nuclear program. (21 de 
enero de 2016). Reuters. Recuperado de http://www.reuters.com/ article/us-northkoreanuclear-parkidUSKCNOV009D

Szalontai, B. y Radchenko, S. (2006). North Korea's Efforts to Acquire Nuclear Technology and Nuclear Weapons: Evidence from Russian and Hungarian Archives. Nuclear Ploriferation International History Project Working Paper 53.

The Atlas of Economic Complexity (2018). What did North Korea export in 2016? Harvard University. Recuperado de http://atlas.cid.harvard.edu/explore/?country $=178 \& p$ artner $=$ undefined \&product $=$ unde fined\&productClass $=$ HS\&startYea $r=$ undefined\&target $=$ Product\&ye ar $=2016$

US says "no intention" to attack N. Korea. (29 de agosto de 2003). China Daily. Recuperado de http://www. chinadaily.com.cn/en/doc/200308/29/content_259636.htm

Waltz, K. (1988). Teoría de la política internacional. Buenos Aires: GEL.

Wolf, C., Wang, X. y Warner, E. (2013). China's Foreign Aid and Government-Sponsored Investment Activities Scale, Content, Destinations, and Implications. Santa Monica, CA: RAND Corporation. Recuperado de https://www.rand.org/pubs/ research_reports/RR118.html
Yi, W. (26 de agosto de 2003). Vice Foreign Minister Wang Yi, Head of the Chinese Delegation to the Six-Party Beijing Talks, Receives a Joint Interview by Xinhua News Agency, People's Daily, CCTV, CRI and China Daily. Permanent Mission of the People's Republic of China to the UN. Recuperado de http://www.china-un.org/eng/zt/ ch/t25372.htm

Yi, W. (18 de septiembre de 2013a). Stay Committed to the Six-Party Talks for Lasting Peace. Ministry of Foreign Affairs of the People's Republic of China. Recuperado de https://www.fmprc. gov.cn/mfa_eng/wjb_663304/ wjbz_663308/2461_663310/ t1078892.shtml

Yi, W. (30 de agosto de 2013b). Vice FM Wang Yi, Head of Chinese Delegation to the Six-party Talks Gives a Press Conference. Permanent Mission of the People's Republic of China to the UN. Recuperado de http://www.china-un.org/eng/zt/ch/ t25552.htm

Yi, W. (9 de marzo de 2016). Press Conference in the Fourth Session of the Twelfth National People's Congress. Ministry of Foreign Affairs of the People's Republic of China. Recuperado de http://www.fmprc.gov.cn/mfa_eng/zxxx_662805/ t1346238.shtml 
